\title{
Management of COVID-19 ICU-survivors in primary care: - a narrative review
}

\author{
KFR Schmidt ${ }^{1,2^{*}}$, J. Gensichen ${ }^{3}$, S. Gehrke-Beck ${ }^{1}$, R. P. Kosilek ${ }^{3}$, F. Kühne ${ }^{3}$, C Heintze $^{1}$, L. M. Baldwin ${ }^{4}$ and \\ D. M. Needham ${ }^{5}$
}

\begin{abstract}
Many survivors of critical illness suffer from long-lasting physical, cognitive, and mental health sequelae. The number of affected patients is expected to markedly increase due to the COVID-19 pandemic. Many ICU survivors receive longterm care from a primary care physician. Hence, awareness and appropriate management of these sequelae is crucial. An interdisciplinary authorship team participated in a narrative literature review to identify key issues in managing COVID-19 ICU-survivors in primary care. The aim of this perspective paper is to synthesize important literature to understand and manage sequelae of critical illness due to COVID-19 in the primary care setting.
\end{abstract}

Keywords: Primary care, Post-intensive-care-syndrome, COVID-19

\section{Background}

The COVID-19 pandemic is affecting primary care in many ways, including shortages of personal protective equipment, triage with limited resources, lack of therapeutic strategies, use of telemedicine, and economic constraints. However, another aspect of the pandemic is coming into view: recovery after treatment in an intensive care unit (ICU). Considerably more patients survive than die from the COVID-19, some after a long stay in an ICU. From more than two decades of research, we have substantial evidence that many ICU survivors do not return to their previous health status: Multiple physical, cognitive and mental health sequelae, known as the Post-Intensive Care Syndrome (PICS) [1], impact survivors' return to work or meaningful activities for months or even years.

Similar to most chronically ill patients, the majority of ICU survivors continue to receive long-term aftercare

\footnotetext{
*Correspondence: Konrad.Schmidt@charite.de; Konrad.Schmidt@med.unijena.de

${ }^{1}$ Institute of General Practice and Family Medicine, Charité University Medicine Berlin, Berlin, Germany

${ }^{2}$ Institute of General Practice and Family Medicine, Jena University Hospital, Jena, Germany

Full list of author information is available at the end of the article
}

from their primary care physicians. Within primary care, awareness of PICS may have been low: Until now, ICU survivors represent only a very small percentage of primary care patients. In addition, clinical signs associated with PICS are often similar to those caused by other chronic diseases. Furthermore, information flow between intensive care and primary care is impeded as these specialties represent the opposite ends of a spectrum within medical care. This existing situation may change with increasing numbers of COVID-19 survivors being discharged home and needing ongoing care. The Chartered Society of Physiotherapy even predicts "a tsunami of rehabilitation needs" [2] and also primary care physicians are likely to encounter substantially increased numbers of post-ICU COVID-19 patients. Consequently, the British Faculty of Intensive Care Medicine (FICM) realizes "a real opportunity to ensure full implementation of existing hospital and community based rehabilitation services for people recovering from critical illness." [3].

The aim of this perspective paper is to synthesize important literature to support primary care providers in understanding and managing sequelae of critical illness due to COVID-19. 


\section{Methods}

We convened an interdisciplinary authorship team that has collaborated for up to $10 \mathrm{y}$ on post-ICU aftercare research. In addition, several authors have been involved in guideline and review articles on post-ICU and post COVID-19 care [1, 4-6].

To prepare this perspective paper, the primary author identified and described key categories of challenges in post-ICU care of COVID-19 survivors. These categories were circulated to the authorship team for discussion and iterative refinement, until agreement was reached. Narrative or non-systematic literature reviews are employed to help support expert statements [7]. Thus, a narrative literature review was used to identify diagnostic and therapeutic strategies for each of these challenges. PubMed and Scholar databases were searched up to January 2021 on post-ICU and post COVID-19 care; the search strategy focused on systematic reviews, metaanalyses, national guidelines and randomized controlled trials, if available. In total, 63 relevant papers were identified. The resulting expert opinions are intended to support primary care for patients who experience sequelae of critical illness due to Covid-19.

\section{Results}

\section{Post-ICU care}

So far, evidence supporting structured ICU after-care is inconsistent: In randomized trials, outpatient post-ICU clinics have failed to demonstrate improved patient outcomes [8]. However, a primary care clinical assessment, within 90 days after hospitalization, is recommended by the UK's NICE guideline [9], including reconciliation or elimination of inappropriate medications. To ensure optimal primary care assessment, effective information transfer and networks are needed. For example, detailed discharge notes from the hospital are essential, including data on respiration, mobility, swallowing, activities of daily life, as well as cognition and mental health status. Discharge letters handed out to the patient directly [10] provide a possible way to improve this transition between hospital-based and primary care.

Since recovery pathways and underlying diseases differ widely among ICU survivors, the reassessment process must be adapted individually. Table 1 provides major post-intensive care complications, including selected key symptoms, risk factors, screening instruments and treatment options. In summary, three key dimensions are recommended for primary care providers caring for post-ICU patients, inspired by the PICS concept: [1].

- Motor function, swallowing, and physical status.

- Mental health and cognitive function.

- Family and social health.

\section{Motor function, swallowing and physical status}

ICU-Acquired Weakness (ICUAW), commonly caused either alone, or in combination, by muscle atrophy, Critical Illness Polyneuropathy (CIP) or Critical Illness Myopathy (CIM) has great impact on mobility and other activities of daily living [34]. Within primary care, early initiation of frequent physical therapy, occupational therapy, and nutrition advice may facilitate recovery from these conditions.

Around one third of patients with long-term mechanical ventilation have persisting dysphagia symptoms [17], increasing the risk for aspiration and pneumonia. Assessment by a speech and language therapist/ pathologist (SLP), including instrumental assessment of swallowing, may have occurred in the hospital setting prior to discharge. The need for ongoing speech and language therapy should be evaluated in the primary care setting.

In patients with Acute Respiratory Distress Syndrome (ARDS), which is common in severe cases of COVID-19 infections, long-lasting, clinically-important impairments in pulmonary function are surprisingly uncommon [35]. However, combined impairment in physical and cardiopulmonary status contribute to long-lasting reduction of exercise capacity (compared to a matched control group), as measured by the 6-Minute Walk Test [14]. (If the minimum $12 \mathrm{~m}$-walkway is not available in the primary care practice, the 4-Meter Gait Speed Test may be considered.) [15] Early experiences among COVID-19 survivors suggest that early pulmonary rehabilitation, including breathing and movement training, may enhance recovery of respiratory and physical function [36].

After assessment of cardiorespiratory function by the primary care physician, breathing exercises and physical rehabilitation can be guided by physiotherapists, occupational therapists and/or primary care physician assistants, with expert input from physiatrists, as needed.

Beyond that, almost every organ system can be affected after intensive care, as listed for COVID-19 survivors in a Position Statement from the FICM [3]. Presenting all possible complications would go beyond the scope of this article. However, it is especially important to actively address potentially neglected topics, such as erectile dysfunction in male patients.

\section{Mental health and cognitive function}

Many patients experience critical illness and ICU treatment as life-threatening events. New or worsened symptoms of depression, anxiety and/or post-traumatic stress disorder (PTSD) are common in the longterm. The etiology is complex - delirium, intrusive memories, use of sedative medications (e.g. benzodiazepines) and prior psychiatric history are commonly reported risk factors [21, 37]. Pandemicrelated environmental factors, such as contact isolation, crisis mentality or overcrowded ICUs may heighten this risk $[3,38]$. According to an observational study from Wuhan, 

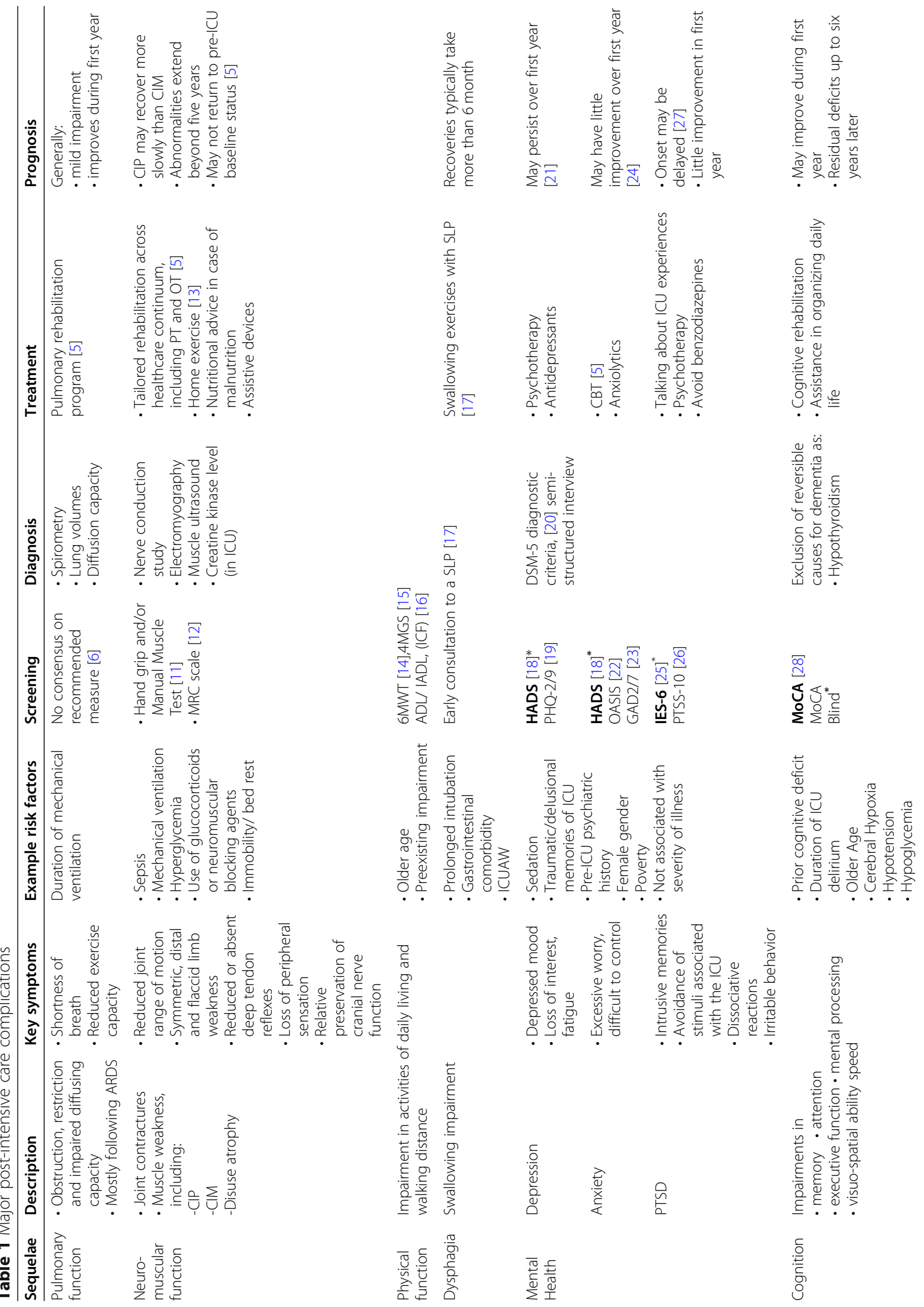


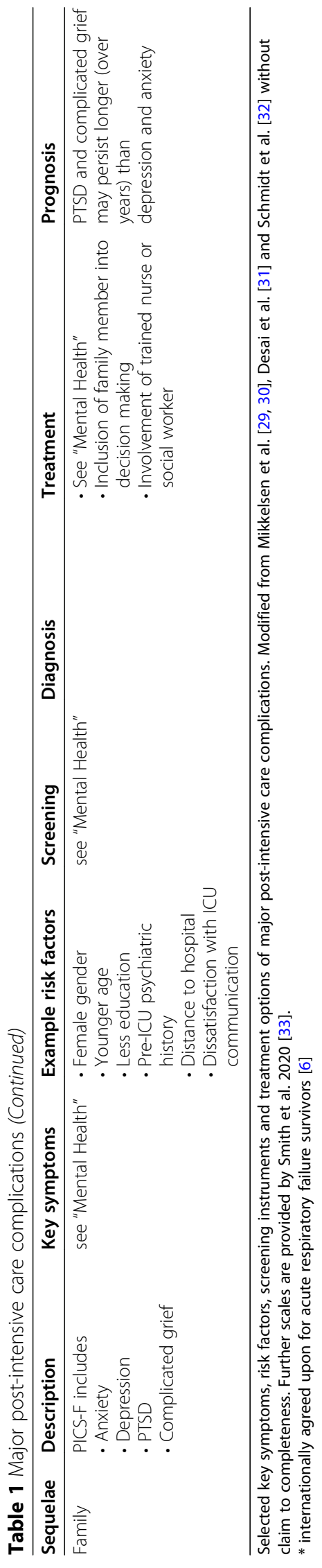


almost all COVID-19 survivors showed symptoms of posttraumatic stress [39]. Psychiatrists expect upcoming rates of PTSD related to the pandemic similar to large scale disasters [40].

As many affected patients may avoid talking about these experiences, a proactive exploration of such symptoms, by the primary care physician, may be required [41], ideally supported by use of screening questionnaires [42], see Table 1. Talking about the ICU experience, and being listened to, are considered to be helpful - ideally using an ICU diary, if available [41]. Patients with severe or persistent symptoms may benefit from referral to a psychologist, psychiatrist or other mental health clinician. Among others, cognitive therapy has been highlighted recently to be applied in PTSD following critical illness [43].

Neurocognitive impairment among ICU survivors, associated with a history of delirium, hypoxia and/or hypotension in the ICU, can lead to significant impairment in daily life [44]. Common aspects of this impairment include reduced attention, memory and executive function. Reversible causes for cognitive impairment (e.g. hypothyroidism) should be excluded. Once this is done, the primary care physician may contribute to quality of life by assisting the patient and family in practically organizing daily life, along with specialized help from neuropsychologists and/ or cognitive rehabilitation therapy.

\section{Family and social health}

Family members often experience the ICU course of their loved one closely. Thus, around 30\% of them may suffer from relevant symptoms of anxiety, PTSD or depression during or after a critical illness of a relative [45]. Therefore, a separate term was introduced to raise awareness of these problems: PICS-Family [1]. Restricted access to inpatients in time of the pandemic may increase this particular risk [38]. Consequently, assessment of psychological symptoms should also be extended to a patient's close family members [46]. Even if challenging due to time constraints, this may be especially necessary in the primary care setting.

Workplace reintegration is another important issue for consideration: Approximately $40 \%$ of critical illness survivors are unemployed at 12 months after discharge, while those who return to work might experience adverse changes to occupation or employment status [47]. Unemployment, in general, is associated with adverse mental health outcomes and might further aggravate the patients' status. During the COVID-10 pandemic, it is unclear how the unprecedented economic shut-down may further exacerbate unemployment in ICU survivors.

Until now, there has been little evidence regarding specific interventions promoting return to work after critical illness. However, affected patients might benefit from multidisciplinary rehabilitation, including close coordination between their primary care physician, employer, and occupational medicine specialists [47].

\section{Options for support}

ICU follow-up within primary care is challenging; additional support for patients and primary care providers is needed. Continuity of care in times of contact restrictions will be expanded increasingly to the virtual space. Patients may receive support by mobile applications promoting behavioural activation, breathing exercises or mindfulness [48]. Even a telephone-based intervention has been proven to increase coping skills following ICU discharge [49]. A growing selection of web resources supports diagnosis and treatment planning. For example, a recent "Practice Pointer" published in the BMJ provides general advice for management of post-acute COVID-19 patients in primary care [50]. Progress in a patient's status can be tracked using a 'functional reconciliation checklist', which is considered to be useful, although its impact has not been evaluated [51]. Further resources are shown in Table 2.

Table 2 Selection of web resources on ICU follow up (adapted from Tingey et al. [52])

\begin{tabular}{|c|c|c|c|}
\hline Organisation & Focus & Target group & Link \\
\hline $\begin{array}{l}\text { Johns Hopkins University Pulmonary \& } \\
\text { Critical Care Medicine, Baltimore, MD }\end{array}$ & $\begin{array}{l}\text { Outcomes after Critical } \\
\text { Illness and Surgery (OACIS) }\end{array}$ & Medical professionals & $\begin{array}{l}\text { www.improveLTO.com } \\
\text { https://www.hopkinsmedicine.org/pulmonary/research/ } \\
\text { outcomes-after-critical-illness/index.html }\end{array}$ \\
\hline Wolters Kluwer, The Netherlands & $\begin{array}{l}\text { Rehabilitation after } \\
\text { Critical Illness }\end{array}$ & & $\begin{array}{l}\text { https://www.uptodate.com/contents/post-intensive-care- } \\
\text { syndrome-pics\#H457093 }\end{array}$ \\
\hline $\begin{array}{l}\text { National Institute for Health and } \\
\text { Care Excellence (NICE), UK }\end{array}$ & & & https://www.nice.org.uk/guidance/cg83 \\
\hline $\begin{array}{l}\text { Intensive care patient support charity } \\
\text { (ICUsteps), London, UK }\end{array}$ & & Patients and Families & https://www.icusteps.org \\
\hline $\begin{array}{l}\text { Society of Critical Care Medicine } \\
\text { (SCCM), Chicago, IL }\end{array}$ & & & https://www.sccm.org/MylCUCare/Home \\
\hline $\begin{array}{l}\text { Critical Illness, Brain Dysfunction, and } \\
\text { Survivorship Center (CIBS), Nashville, TN }\end{array}$ & Delirium & & https://www.icudelirium.org \\
\hline ARDS Foundation, Dundee, IL & ARDS & & https://ardsglobal.org/other-resources/ \\
\hline
\end{tabular}


Standardized screening instruments possibly facilitate diagnostic assessment of impairments associated with PICS, as internationally agreed upon for acute respiratory failure survivors [6], see also Table 1. Patients with advanced age, preexisting chronic conditions, high intensity of intensive care and also ethnic minority background [29] are at highest risk for impairments; use of screening instruments should be focused on these groups. In addition, patients and their relatives can be referred to an intensive care support group and or follow-up clinic, if available. Furthermore, a detailed exercise instruction guide has been published to help COVID-19 survivors in physical rehabilitation at home [13].

However, primary care physicians need training in managing ICU survivors, as others have noted [42]. The authors advocate for integration of post-ICU care into primary care training and continuing medical education. Among other ideas, longitudinal clerkships to follow patient's courses from ICU to primary care may provide a possible approach.

\section{Limitations}

The information presented in this narrative review does not represent a clinical practice guideline, as it is limited by the non-systematic identification of studies as well as the missing formal evaluation of the risk of bias of the selected literature. Given the rapid development of research during the pandemic, new data may emerge and change any information presented herein. However, we consider the principle of multi-disciplinary collaboration will continue to be an important guiding principle in the field, with primary care physicians playing a key role in post-ICU management.

\section{Conclusion}

Survivors of critical illness are at risk for long-lasting physical, cognitive and mental health sequelae. With the COVID-19 pandemic, these issues will grow in importance. Given the complexity and heterogeneity of the clinical course of ICU survivors, ICU follow-up requires multidisciplinary collaboration, which may be catalyzed by the COVID-19 pandemic. Primary care physicians play a key role in the management of post-ICU sequelae - due to their expertise in comprehensive medicine, coordination of care, embracing patients' self-care and long-term knowledge of patients' and their families' medical history. The COVID-19 pandemic emphasizes the need for further research into post-ICU follow-up care, and its challenges in primary care.

\section{Abbreviations}

4MGS: 4 Meter Gait Speed Test [15]; 6MWT: 6 Minute Walk Test [14]; ADL IADL: (Instrumental) Activities of daily living; ARDS: Acute Respiratory Distress Syndrome; CBT: Cognitive-Behavioral Therapy; CIM: Critical Illness Myopathy; CIP: Critical IIIness Polyneuropathy; GAD-2/7: Generalized Anxiety Disorder 2/ 7-item [49]; HADS: Hospital Anxiety and Depression Scale [18]; ICF: World Health Organization's International Classification of Functioning, Disability and Health Framework [16]; ICU: Intensive Care Unit; ICUAW: ICU-Acquired Weakness; IES-6: Impact of Event Scale- 6 item version [50]; MoCa

(Blind): Montreal Cognitive Assessment (Blind) [24]; MRC: Medical Research Council [12]; OASIS: Overall Anxiety and Impairment Scale [21];

OT: Occupational Therapy; PHQ-2/9: Patient Health Questionnaire-2/9 [51]; PICS-F: Post-Intensive Care Syndrome-Family; PT: Physiotherapy; PTSD: PostTraumatic Stress Disorder; PTSS-10: Posttraumatic Stress Scale-10 [52]; SIRS: Systemic Inflammatory Response Syndrome; SLP: Speech language pathologist

\section{Acknowledgements}

We thank Miriam Hesse and Michelle Beuthling for technical support and Inga Petruschke for proof-reading.

\section{Authors' contributions}

KS, JG and RPK discussed the scope and design of the article; LMB and DMN contributed conceptual perspectives; KS drafted the initial manuscript with contributions of SGB, RPK and FK; ChrH, DMN, JG, SGB, LMB and RPK revised the manuscript critical and gave important intellectual content. The corresponding author attests that all listed authors meet the authorship criteria. All authors approved the final manuscript.

Funding

Open Access funding enabled and organized by Projekt DEAL.

Availability of data and materials

All: not applicable.

\section{Declarations}

Competing interests

The authors declare that they have no competing interests.

\section{Author details}

${ }^{1}$ Institute of General Practice and Family Medicine, Charité University Medicine Berlin, Berlin, Germany. ${ }^{2}$ Institute of General Practice and Family Medicine, Jena University Hospital, Jena, Germany. ${ }^{3}$ Institute of General Practice and Family Medicine, University Hospital of the Ludwig-Maximilians-University, Munich, Germany. ${ }^{4}$ Department of Family Medicine, University of Washington School of Medicine, Seattle, WA, USA. ${ }^{5}$ Division of Pulmonary and Critical Care Medicine, Department of Physical Medicine and Rehabilitation, School of Medicine, Johns Hopkins University, Baltimore, MD, USA.

Received: 11 February 2021 Accepted: 19 May 2021

Published online: 24 July 2021

\section{References}

1. Needham DM, Davidson J, Cohen $H$, Hopkins RO, Weinert C, Wunsch $H$, et al. Improving long-term outcomes after discharge from intensive care unit: report from a stakeholders' conference. Crit Care Med. 2012;40(2):5029. https://doi.org/10.1097/CCM.0b013e318232da75.

2. Thornton J. Covid-19: the challenge of patient rehabilitation after intensive care. BMJ. 2020;369:m1787.

3. FICM Position Statement and Provisional Guidance: Recovery and Rehabilitation for Patients Following the Pandemic [https://www.ficm.ac.uk/ news-events-education/news/provisional-guidance-recovery-and-rehabilita tion-patients-following/].

4. Blankenfeld Hea: Neues Coronavirus (SARS-CoV-2)-Informationen für die hausärztliche Praxis. In: Guidelines of the German College of General Practitioners and Family Physicians vol. Version 14 2020: 053-054.

5. Korupolu R, Francisco G, Levin H, Needham D. Rehabilitation of critically ill COVID-19 survivors. J Int Soc Phys Rehabil Med. 2020;3(2):45-52. https://doi. org/10.4103/jisprm.jisprm_8_20.

6. Needham DM, Sepulveda KA, Dinglas VD, Chessare CM, Friedman LA, Bingham CO III, et al. Core outcome measures for clinical research in acute respiratory failure survivors. An international modified Delphi consensus study. Am J Respir Crit Care Med. 2017;196(9):1122-30. https://doi.org/10.11 64/rccm.201702-03720C. 
7. Lilley H, Payne R, Fox D, Brown RJ, Fountain D. Systematic Vs. Nonsystematic literature review methodology for publication in leading journals. Value Health. 2020;23:S614. https://doi.org/10.1016/j.jval.2020.08.1280.

8. Schofield-Robinson OJ, Lewis SR, Smith AF, McPeake J, Alderson P. Followup services for improving long-term outcomes in intensive care unit (ICU) survivors. Cochrane Database Syst Rev. 2018;11:Cd012701.

9. Rehabilitation after critical illness in adults [https://www.nice.org.uk/guida nce/cg83].

10. Hoffman K, Thomas A, Brett S. Clinical Pathways for the Continuum of Rehabilitation. In: Stevens RD, Hart N, editors. Textbook of post-ICU medicine: the legacy of critical care, Oxford University Press. Herridge: MS; 2014. p. 546-58.

11. Ali NA, O'Brien JM Jr, Hoffmann SP, Phillips G, Garland A, et al. Acquired weakness, handgrip strength, and mortality in critically ill patients. Am J Respir Crit Care Med. 2008;178(3):261-8. https://doi.org/10.1164/rccm.2 00712-18290C.

12. Paternostro-Sluga T, Grim-Stieger M, Posch M, Schuhfried O, Vacariu G, Mittermaier C, et al. Reliability and validity of the Medical Research Council (MRC) scale and a modified scale for testing muscle strength in patients with radial palsy. J Rehabil Med. 2008;40(8):665-71. https://doi.org/10.2340/1 6501977-0235.

13. Ambrose A, Bartels M, Verghese T, Verghese J. Patient and caregiver guide to managing COVID-19 patients at home. J Int Soc Phys Rehabil Med. 2020; 3(2):53-68. https://doi.org/10.4103/jisprm.jisprm_4_20.

14. Parry SM, Nalamalapu SR, Nunna K, Rabiee A, Needham DM, et al. Sixminute walk distance after critical illness: a systematic review and metaanalysis. J Intensive Care Med. 2021;36(3):343-51. https://doi.org/10.1177/ 0885066619885838.

15. Chan KS, Aronson Friedman L, Dinglas VD, Hough CL, Morris PE, MendezTellez PA, et al. Evaluating physical outcomes in acute respiratory distress syndrome survivors: validity, responsiveness, and minimal important difference of 4-meter gait speed test. Crit Care Med. 2016:44(5):859-68. https://doi.org/10.1097/CCM.0000000000001760.

16. Ohtake PJ, Lee AC, Scott JC, Hinman RS, Ali NA, Hinkson CR, et al. Physical impairments associated with post-intensive care syndrome: systematic review based on the World Health Organization's international classification of functioning, Disability and Health Framework. Phys Ther. 2018;98(8):63145. https://doi.org/10.1093/pti/pzy059.

17. Brodsky MB, Nollet JL, Spronk PE, Gonzalez-Fernandez M. Prevalence, Pathophysiology, Diagnostic Modalities and Treatment Options for Dysphagia in Critically III Patients. Am J Phys Med Rehabil. 2020;99:1164-70.

18. Snaith R, Zigmond A. Hospital anxiety and depression scale (HADS). In: Handbook of psychiatric measures. Washington: American Psychiatric Association; 2000. p. 547-8.

19. Kroenke K, Spitzer RL, Williams JB, Monahan PO, Löwe B. Anxiety disorders in primary care: prevalence, impairment, comorbidity, and detection. Ann Intern Med. 2007;146(5):317-25. https://doi.org/10.7326/0003-4819-146-5-2 00703060-00004

20. American Psychiatric Association: Diagnostic and Statistical Manual of Mental Disorders, Fifth Edition (DSM-5). Arlington; 2013.

21. Rabiee A, Nikayin S, Hashem MD, Huang M, Dinglas VD, Bienvenu OJ, et al. Depressive symptoms after critical illness: a systematic review and metaanalysis. Crit Care Med. 2016;44(9):1744-53. https://doi.org/10.1097/CCM. 0000000000001811.

22. Norman SB, Cissell SH, Means-Christensen AJ, Stein MB. Development and validation of an overall anxiety severity and impairment scale (OASIS). Depress Anxiety. 2006;23(4):245-9. https://doi.org/10.1002/da.20182.

23. Plummer F, Manea L, Trepel D, McMillan D. Screening for anxiety disorders with the GAD-7 and GAD-2: a systematic review and diagnostic metaanalysis. Gen Hosp Psychiatry. 2016;39:24-31. https://doi.org/10.1016/j. genhosppsych.2015.11.005.

24. Nikayin S, Rabiee A, Hashem MD, Huang M, Bienvenu OJ, Turnbull AE, et al. Anxiety symptoms in survivors of critical illness: a systematic review and meta-analysis. Gen Hosp Psychiatry. 2016;43:23-9. https://doi.org/10.1016/j. genhosppsych.2016.08.005

25. Hosey MM, Leoutsakos JS, Li X, Dinglas VD, Bienvenu OJ, et al. Screening for posttraumatic stress disorder in ARDS survivors: validation of the impact of event Scale-6 (IES-6). Crit Care. 2019;23(1):276. https://doi.org/10.1186/s13 054-019-2553-z.

26. Stoll C, Kapfhammer HP, Rothenhäusler HB, Haller M, Briegel J, Schmidt M, et al. Sensitivity and specificity of a screening test to document traumatic experiences and to diagnose post-traumatic stress disorder in ARDS patients after intensive care treatment. Intensive Care Med. 1999;25(7):697704. https://doi.org/10.1007/s001340050932.

27. Schmidt KF, Schwarzkopf D, Baldwin LM, Brunkhorst FM, Freytag A et al: Long-Term Courses of Sepsis Survivors: Effects of a Primary Care Management Intervention. Am J Med 2020, 133(3): 381-385.e385.

28. Nasreddine ZS, Phillips NA, Bedirian V, Charbonneau S, Whitehead V, et al. The Montreal cognitive assessment, MoCA: a brief screening tool for mild cognitive impairment. J Am Geriatr Soc. 2005;53(4):695-9. https://doi.org/1 0.1111/j.1532-5415.2005.53221.x.

29. Mikkelsen ME, Still M, Anderson BJ, Bienvenu OJ, Brodsky MB, Brummel N, et al. Society of Critical Care Medicine's international consensus conference on prediction and identification of long-term impairments after critical illness. Crit Care Med. 2020;48(11):1670-9. https://doi.org/10.1097/CCM. 0000000000004586

30. Mikkelsen ME, Netzer G, Iwashyna T: Post-intensive care syndrome (PICS). In: edn. Edited by Post T. UpToDate; Waltham. (Accessed on June 16, 2020); 2020: 1-29.

31. Desai SV, Law TJ, Needham DM. Long-term complications of critical care. Crit Care Med. 2011;39(2):371-9. https://doi.org/10.1097/CCM.0b013 e3181fd66e5.

32. Schmidt KFR, Gehrke-Beck S: Transitions to primary care. In: Improving Critical Care Survivorship. Editors: Haines KJ, McPeake J, Sevin CM. Springer Nature 2021.

33. Smith EMT, Lee ACW, Smith JM, Thiele A, Zeleznik H et al.: COVID-19 and post-intensive care syndrome: community-based care for ICU survivors. Home Health Care Manag Pract 2020, 0(0):1084822320974956.

34. Jolley SE, Bunnell AE, Hough CL. ICU-acquired weakness. Chest. 2016;150(5): 1129-40. https://doi.org/10.1016/j.chest.2016.03.045.

35. Herridge MS, Tansey CM, Matte A, Tomlinson G, Diaz-Granados N, et al. Functional disability 5 years after acute respiratory distress syndrome. $N$ Engl J Med. 2011;364(14):1293-304. https://doi.org/10.1056/NEJMoa1011802.

36. Liu K, Zhang W, Yang Y, Zhang J, Li Y, Chen Y. Respiratory rehabilitation in elderly patients with COVID-19: a randomized controlled study. Complement Ther Clin Pract. 2020;39:101166. https://doi.org/10.1016/j.ctcp.2 020.101166

37. Wade D, Hardy R, Howell D, Mythen M. Identifying clinical and acute psychological risk factors for PTSD after critical care: a systematic review. Minerva Anestesiol. 2013;79(8):944-63.

38. Biehl M, Sese D. Post-intensive care syndrome and COVID-19 - implications post pandemic. Cleve Clin J Med. 2020. https://doi.org/10.3949/ccjm.87a. ccc055.

39. Bo HX, Li W, Yang $Y$, Wang $Y$, Zhang $Q$, et al. Posttraumatic stress symptoms and attitude toward crisis mental health services among clinically stable patients with COVID-19 in China. Psychol Med. 2020:1-2.

40. DePierro J, Lowe S, Katz C. Lessons learned from 9/11: mental health perspectives on the COVID-19 pandemic. Psychiatry Res. 2020;288:113024. https://doi.org/10.1016/j.psychres.2020.113024.

41. Taylor AK, Fothergill C, Chew-Graham CA, Patel S, Krige A. Identification of post-traumatic stress disorder following ICU. Br J Gen Pract. 2019;69(680): 154-5. https://doi.org/10.3399/bjgp19X701765.

42. Stam HJ, Stucki G, Bickenbach J. Covid-19 and Post Intensive Care Syndrome: A Call for Action. J Rehabil Med. 2020;52(4):jrm00044.

43. Murray H, Grey N, Wild J, Warnock-Parkes E, Kerr A, Clark DM, et al. Cognitive therapy for post-traumatic stress disorder following critical illness and intensive care unit admission. Cogn Behav Ther. 2020;13. https://doi. org/10.1017/S1754470X2000015X

44. Hopkins RO, Weaver LK, Pope D, Orme JF, Bigler ED, et al. Neuropsychological sequelae and impaired health status in survivors of severe acute respiratory distress syndrome. Am J Respir Crit Care Med. 1999; 160(1):50-6. https://doi.org/10.1164/ajrccm.160.1.9708059.

45. Schmidt M, Azoulay E. Having a loved one in the ICU: the forgotten family. Curr Opin Crit Care. 2012;18(5):540-7. https://doi.org/10.1097/MCC.0b013e32 $8357 f 141$

46. Kiernan F. Care of ICU survivors in the community: a guide for GPs. Br I Gen Pract. 2017:67(663):477-8. https://doi.org/10.3399/bjgp17X693029.

47. Kamdar BB, Suri R, Suchyta MR, Digrande KF, Sherwood KD, Colantuoni E, et al. Return to work after critical illness: a systematic review and meta-analysis. Thorax. 2020;75(1):17-27. https://doi.org/10.1136/thoraxjnl-2019-213803.

48. Parker AM, Nelliot A, Chessare CM, Malik AM, Koneru M, Hosey MM, et al. Usability and acceptability of a mobile application prototype for a 
combined behavioural activation and physical rehabilitation intervention in acute respiratory failure survivors. Aust Crit Care. 2020;33(6):511-7. https:// doi.org/10.1016/j.aucc.2020.02.010.

49. Cox CE, Porter LS, Hough CL, White DB, Kahn JM, Carson SS, et al.

Development and preliminary evaluation of a telephone-based coping skills training intervention for survivors of acute lung injury and their informal caregivers. Intensive Care Med. 2012;38(8):1289-97. https://doi.org/10.1007/ s00134-012-2567-3.

50. Greenhalgh T, Knight M, A'Court C, Buxton M, Husain L. Management of post-acute covid-19 in primary care. BMJ. 2020;370:m3026.

51. Harvey MA, Davidson JE. Postintensive Care Syndrome: Right Care, Right Now ... and Later. Crit Care Med. 2016;44(2):381-5. https://doi.org/10.1097/ CCM.0000000000001531

52. Tingey JL, Bentley JA, Hosey MM. COVID-19: understanding and mitigating trauma in ICU survivors. Psychol Trauma. 2020;12(S1):S100-4. https://doi. org/10.1037/tra0000884.

\section{Publisher's Note}

Springer Nature remains neutral with regard to jurisdictional claims in published maps and institutional affiliations.

Ready to submit your research? Choose BMC and benefit from:

- fast, convenient online submission

- thorough peer review by experienced researchers in your field

- rapid publication on acceptance

- support for research data, including large and complex data types

- gold Open Access which fosters wider collaboration and increased citations

- maximum visibility for your research: over $100 \mathrm{M}$ website views per year

At BMC, research is always in progress.

Learn more biomedcentral.com/submissions 